\title{
O MUNICÍPIO E O DIREITO À CIDADE: POLÍTICAS PÚBLICAS TRIBUTÁRIAS E O ENFRENTAMENTO DA EXCLUSÃO URBANA NO ESPAÇO LOCAL
}

THE MUNICIPALITY AND THE RIGHT TO THE CITY: PUBLIC TAX POLICIES AND THE FACING OF URBAN EXCLUSION IN LOCAL SPACE

\author{
Ricardo Hermany ${ }^{1}$ \\ Guilherme Estima Giacobbo ${ }^{2}$
}

\section{Resumo}

O artigo tem como delimitação do tema a possibilidade de implementação de políticas públicas tributárias, por parte do ente municipal que visem à mitigação da exclusão social, especialmente nas áreas que se convencionou chamar de "cidade ilegal". O problema de pesquisa questiona se o município, enquanto ente federado em busca da consolidação de sua autonomia plena pode atuar no enfrentamento de desigualdades históricas, por meio da criação de políticas tributárias direcionadas ao uso e ocupação do solo, de modo a garantir acréscimo de receitas para aplicação em infraestrutura, regularização de ocupações clandestinas consolidadas e viabilização do planejamento urbano. Utilizando-se do método dedutivo, o trabalho se desenvolve sob a premissa de que o município, vinculado aos objetivos constitucionais, deve desenvolver políticas tributárias locais aptas a enfrentar a exclusão urbana e mitigar desigualdades históricas, comuns entre os países de capitalismo periférico. No primeiro ponto há uma contextualização da formação das cidades clandestinas e do problema habitacional, passando-se à análise da tendência contemporânea de valorização da autonomia local e descentralização, que coloca o município em protagonismo no atendimento das demandas sociais. No derradeiro capítulo apontam-se estratégias aplicáveis às políticas tributárias municipais visando à redução de desigualdades espaciais, através de um planejamento territorial democrático, bem como se avaliam os principais desafios e entraves à implementação desse tipo de matriz tributária redistributiva.

Palavras-Chave: Descentralização; Direito à Cidade; Espaço Local; Exclusão Urbana; Políticas Públicas Tributárias.

\section{Abstract}

The article has as delimitation of the subject the possibility of implementation of public tax policies, by the municipal entity, that aim at the mitigation of social exclusion, especially in the areas that are known as "illegal city". The research matter questions whether the municipality, as a federated entity seeking to consolidate its full autonomy, can act in the face of historical inequalities, through the creation of tax policies aimed at the use and occupation of the land, in order to guarantee an increase in revenues for application in infrastructure, regularization of

\footnotetext{
${ }^{1}$ Pós-Doutor na Universidade de Lisboa (2011). Professor da graduação e do Programa de Pós-Graduação em Direito- Mestrado/Doutorado da Universidade de Santa Cruz do Sul - UNISC. E-mail: hermany@unisc.br

2 Doutorando em Direito pela Universidade de Santa Cruz do Sul - UNISC. E-mail: guilhermegiacobbo@gmail.com
} 
consolidated clandestine occupations and feasibility of urban planning. Using the deductive method, the work develops under the hypothesis that the municipality, linked to the constitutional objectives, should develop local tax policies able to face the urban exclusion and mitigate historical inequalities, common among countries of peripheral capitalism. In the first point, there is a contextualization of the formation of clandestine cities and of the housing problem, with an analysis of the contemporary tendency to valorize local autonomy and decentralization, which places the municipality in the leading role in meeting social demands. In the last chapter, strategies applicable to municipal tax policies aiming at reducing spatial inequalities through a democratic territorial planning are analyzed, as well as the main challenges and obstacles to the implementation of this type of redistributive tax matrix.

Keywords: Decentralization; Local Space; Right to the City; Urban Exclusion; Public Tax Policies.

\section{CONSIDERAÇÕES INICIAIS}

A partir da promulgação da Constituição da Constituição Federal de 1988 se buscou romper com o paradigma da centralização estatal, fazendo surgir um estado com características mais centrífugas e que resultou na atribuição, ao ente municipal, de uma considerável autonomia - do ponto de vista jurídico-formal - outorgando-o competências para legislar sobre assuntos de interesse local, estabelecer sua lei orgânica e assumir diversas tarefas constitucionais através dos processos de municipalização.

Contudo, apesar da autonomia formal herdada da Constituição, os municípios se veem prensados por uma demanda social crescente, problemas estruturais crônicos e, principalmente, uma capacidade financeira limitada. As cidades, especialmente nos centros urbanos, onde vive aproximadamente $85 \%$ da população brasileira, são fragmentadas: de um lado tem-se a cidade legal, minimamente planejada e assistida dos serviços públicos básicos, com infraestrutura, saneamento, escolas e postos de saúde. Por outro lado, tem-se a existência da cidade clandestina, ocupada por uma grande parte de população cujos salários não contemplam a possibilidade de moradia na cidade legal. Essas ocupações se dão em zonas periféricas, geralmente áreas de risco ou de preservação permanente, onde a população se utiliza de técnicas de autoconstrução nas suas residências, ao revés de qualquer planejamento urbanístico e arquitetônico, atendimento de normas de segurança e observância das regras contidas nos códigos de obras e posturas do município. Mais do que isso, essas zonas também costumam ser "invisíveis", não havendo qualquer tipo de intervenção por parte poder público, exceto a ação repressiva, eventualmente. 
A partir disso, a problema de pesquisa posto se refere à possibilidade concreta dos municípios lidarem com a exclusão urbana por meio de políticas públicas tributárias que façam valer os princípios da função social da propriedade e do direito à cidade, observando as diretrizes do planejamento urbano municipal e resistindo à influência do poder financeiro, à especulação imobiliária e aos lobbies do setor construtivo. Portanto, seria possível conceber uma matriz tributária municipal, calcada na progressividade, apta a desincentivar a especulação imobiliária, ao cumprimento da função social da propriedade de modo a viabilizar uma gestão urbana democrática e englobar os atores historicamente excluídos das zonas periféricas urbanas?

Utilizando-se o método dedutivo, adota-se a premissa de que, apesar dos objetivos constitucionais de redução das desigualdades sociais e erradicação da pobreza serem tarefas de abrangência nacional, o município, enquanto ente institucional local, é corresponsável pela concretização desses objetivos e tem à disposição tributos de sua competência que pode dispor em um arranjo com potencial de mitigação dessas desigualdades, bem como auxiliar no ordenamento territorial urbano frente às pressões mercadológicas imobiliárias. A premissa central parte do pressuposto de que a progressividade em impostos de competência municipal, especialmente o predial e territorial urbano, podem alterar distorções históricas na questão habitacional nas cidades, questionando ainda, confirmada a premissa, os motivos que inviabilizam o desenvolvimento de uma matriz tributária redistributiva e socialmente mais justa.

O trabalho tem o objetivo geral de demonstrar a viabilidade de uma política tributária municipal progressiva, de modo a garantir o cumprimento da função social da propriedade e do direito à cidade, rompendo com a apropriação do planejamento urbano pelo poder econômico das grandes incorporadores e da especulação imobiliária, de modo a permitir uma gestão democrática da cidade, inferindo ainda acerca das correlações ocultas de forças que inviabilizam um novo paradigma de planejamento urbano mais inclusivo. Sendo o município corresponsável pela concretização dos objetivos constitucionais de redução de desigualdades e erradicação da miséria, deve lançar um olhar mais cuidadoso, seguindo as diretrizes do Estatuto da Cidade, sobre a "cidade clandestina" e sobre boa parte da população que não tem acesso aos serviços públicos básicos.

Desse modo, o primeiro ponto do trabalho abordará o contexto contemporâneo de descentralização de funções estatais e valorização da autonomia local, notadamente a partir da Constituição Federal, que elevou o município a categoria de pessoa jurídica de direito público dotado de autonomia e competências próprias, especialmente no que tange aos assuntos de 
interesse local, elaboração de lei orgânica própria, plano diretor, planejamento territorial e gestão urbanística, conforme os princípios constitucionais. Apesar da difícil situação de dependência financeira da União, o município tem um campo próprio de atuação que lhe permite, localmente, enfrentar o contexto de exclusão urbana histórica e perseguir os objetivos constitucionais comuns aos entes federados.

O segundo ponto trata da análise mais particularizada do contexto de crise urbana e exclusão social instalados no Brasil a partir de uma breve abordagem histórica, suas principais causas e as complexidades que envolvem sua resolução. Aborda-se, ainda, o papel central dos municípios no enfrentamento dessas questões, especialmente com o advento do Estatuto da Cidade, bem como algumas estratégias e possibilidades viáveis de atuação e redução do quadro de exclusão urbana e gentrificação nos grandes centros urbanos.

A terceira e ultima parte do trabalho tem a finalidade de trazer apontamentos a serem considerados na formulação de políticas públicas de matriz tributária no âmbito municipal, especialmente na questão de sua progressividade, as quais são passíveis de transformar o quadro de desigualdades históricas, especialmente no contexto dos grandes centros urbanos. Para tanto, se utilizará como matriz teórica autores que tratam da formulação e implementação de políticas públicas, bem como a teoria da progressividade de tributos de Thomas Pikkety, enquanto ferramenta de enfrentamento da desigualdade social, aplicada ao âmbito local.

\section{DESCENTRALIZAÇÃO E AUTONOMIA LOCAL: O NECESSÁRIO PROTAGONISMO DO MUNICÍPIO NO PLANEJAMENTO URBANO DEMOCRÁTICO}

Em um contexto democrático, os governos estão submetidos a múltiplas e complexas demandas sociais que, por vezes, sobrecarregam ou inviabilizam seu atendimento efetivo por meio de ações concretas, ou mesmo o reconhecimento de reivindicações legítimas. Assim, a eficácia de um governo democrático é avaliada por meio de sua capacidade de resolver problemas políticos e conciliar diferentes aspirações na agenda governamental (FERNANDEZ, 2006). Por isso, tão importante quanto o montante de recursos financeiros disponíveis é a gestão e conciliação de interesses conflitantes em um determinado programa governamental ou em uma política pública.

Nesse contexto, pode-se afirmar que o espaço público local, na teoria, figura como ambiente privilegiado de interação social e propício à participação pública, pois é nele que a vida em comunidade se desenvolve, onde as relações sociais são mais bem visualizadas e onde 
o poder público permanece em contato mais direto com os cidadãos. Essa aproximação dos cidadãos à esfera de poder local tem a potencialidade de transformar a dualidade EstadoSociedade em uma relação harmônica e cooperada, instigando um controle social responsivo e passível de fomentar a participação cidadã nos assuntos estatais. No entanto, afastando-se da romântica concepção do "small is beautifull”", não é essa a realidade que se verifica nas capitais e grandes cidades brasileiras, cujo contexto é de fragmentação social, baixíssima participação social e pouco envolvimento comunitário nas oportunidades de interação democrática com a gestão municipal.

Há de se ressaltar que a profunda centralização do poder político e econômico que caracterizava a forma de organização da sociedade brasileira leva, em última instância, a um distanciamento entre as necessidades locais e o conteúdo do desenvolvimento econômico e social. Percebe-se, hoje, que a maioria das ações que concernem às necessidades do dia a dia nas cidades, como a construção e gestão das escolas, a organização de redes de comércio, manutenção e criação de infraestruturas locais, a preservação do meio ambiente, a gestão e o planejamento urbanístico, são passíveis de ser resolvida localmente, não necessitando de intervenção de instâncias centrais de governo, exceto pela dependência financeira do ente local (DOWBOR, 2016, p.26).

A esfera pública é, ou deveria ser, o espaço de comunicação de ideias e projetos que emanam da sociedade e são dirigidas aos tomadores de decisão das instituições estatais. Essa esfera pública encontra-se inserida precisamente entre o Estado e a sociedade:

The public sphere is an essential component of sociopolitical organization because it is the space where people come together as citizens and articulate their autonomous views to influence the political institutions of society. Civil society is the organized expression of these views; and the relationship between the state and civil society is the cornerstone of democracy. Without an effective civil society capable of structuring and channeling citizen debates over diverse ideas and conflicting interests, the state drifts away from its subjects ${ }^{4}$. (CASTELLS, 2008)

O contexto atual de valorização do espaço local "pode ser entendido como parte de um processo de reconstrução da esfera pública, orientado para a democratização da gestão de políticas públicas no país, o qual tem na descentralização um de seus componentes centrais". É

\footnotetext{
${ }^{3} \mathrm{O}$ que é pequeno é belo.

${ }^{4} \mathrm{O}$ espaço público é um componente essencial da organização político-social, porque é o espaço onde as pessoas se reúnem como cidadãos e articulam suas opiniões autônomas para influenciar as instituições políticas da sociedade. A Sociedade Civil é a expressão organizada destes pontos de vista; e a relação entre o Estado e a Sociedade Civil é a pedra angular da democracia. Sem uma Sociedade Civil eficaz, capaz de estruturar e canalizar o debate cidadão sobre diversas ideias e interesses conflitantes, o Estado se afasta de seus objetivos. (Tradução livre)
} 
por isso que os governos locais "têm contribuído para a formatação de novos arranjos institucionais e processos de gestão em que se rompem alguns dos elementos críticos que caracterizavam as políticas sociais até os anos de 1980" (FARAH, 2001, p.132).

A tentativa de conter a crise de legitimidade que o Estado contemporâneo enfrenta, especialmente no Brasil, desvela-se em uma necessidade de substituição do sistema político centralizado por um sistema descentralizado e democrático. Há uma inequívoca tendência de descentralização no ocidente, em termos gerais, onde "independientemente de la forma del Estado que se haya adoptado históricamente, puede decirse que en el mundo occidental democrático, el Estado contemporáneo es un Estado descentralizado o en vías de descentralización" (BREWER-CARIAS, 2003, p. 08).

Descentralizar significa alocar o poder, autoridade e responsabilidade por sistemas políticos, fiscais e administrativos, do centro à periferia. As definições mais comuns de descentralização distinguem suas variáveis, de acordo com o grau de autonomia, podendo se dar, em uma extremidade, onde o centro mantém um forte controle com poder limitado e discricionário em relação aos níveis mais baixos (desconcentração), até a progressiva diminuição do controle central com aumento da discricionariedade local no outro extremo (devolução, ou descentralização estrito senso). A devolução, ou descentralização estrito senso, está associado a uma governança mais democrática. (BRINKERHOFF, 2006 p. 02)

In general, democratic local governance offers both a greater range of decisions and more autonomous decision space within that range to local government actors. However, the specific contours of that democratic space will be strongly influenced by how authority is distributed at the local level$\left.\right|^{5}$. (BRINKERHOFF, 2006 p. 03)

Deflui-se, portanto, que a descentralização implica mais do que capacitar plenamente a gestão municipal, mas, sobretudo, deve abranger o alargamento da "base do sistema de tomada de decisão e aproximar a função pública dos cidadãos, uma vez que não se constitui na simples transferência de competências, mas supõe, também, a distribuição do poder decisório entre o governo municipal e a sociedade" (ALMEIDA, 2014, p. 59).

A descentralização territorial pressupõe que quanto maior a proximidade entre o cargo público responsável e o cidadão, mais fácil será o acesso deste ao primeiro, favorecendo o acesso ao processo de tomada de decisões. Nos estados descentralizados há mais incentivos

\footnotetext{
${ }^{5}$ Em geral, um governo local democrático oferece uma maior variedade de decisões e um espaço de decisão mais autônomo nesse contexto para os atores do espaço local. No entanto, os contornos específicos desse espaço democrático serão fortemente influenciados pela forma como a autoridade é distribuída no nível local. (Tradução livre)
} 
para participar na base do sistema, o que facilita a aparição dos movimentos de caráter territorial. Ao contrário, nos estados fortemente centralizados e com maior capacidade de impor decisões políticas, os atores coletivos devem recorrer ao topo do sistema político para serem ouvidos, o que dificulta sua participação (PEREA; BOSCH, 2014, p. 55).

O Estado contemporâneo tem se caracterizado pela assunção de novas funções institucionais, como as de indução e regulação do desenvolvimento por meio de estratégias inovadoras e democráticas, compartilhando parte de suas responsabilidades com a sociedade. Essa nova forma de atuação estatal o conduz a inaugurar uma nova relação com a Sociedade Civil, baseada, fundamentalmente, nos direitos de participação política e no desenvolvimento de instrumentos que possibilitem o exercício efetivo dessa participação (LEAL, 2005).

Entretanto, apenas torna-se factível se referir à descentralização do poder central e democratização do espaço local quando tem elementos de base jurídica e constitucional para tal. Tornar-se-ia infértil a discussão e a proposição de alternativas para a democratização do poder local se não houvesse o que democratizar. Assim, o ente municipal, representando o nível institucional mais próximo ao cidadão, representa o poder local, daí porque só faria sentido tratar deste tema caso o ente municipal estivesse dotado de autonomia e poder passível de ser compartilhado com os cidadãos.

Nesse contexto, a Constituição Federal, tratando dos princípios fundamentais em seu artigo inicial, dispôs que "A República Federativa do Brasil, formada pela união indissolúvel dos Estados e Municípios e do Distrito Federal, constitui-se em Estado Democrático de Direito". Vislumbra-se deste dispositivo que a federação está consubstanciada como princípio fundamental da república, vinculando, por conseguinte, o desenvolvimento sistemático da organização política, alçando o sistema federativo, como cláusula pétrea ${ }^{6}$.

Esse federalismo, garantido constitucionalmente, pode ser compreendido como a forma de organização estatal - ou sistema político - em que agrupamentos territoriais e políticos se unem para originar uma organização de maior amplitude. No Estado federal, os estados-membros que fazem parte da União mantêm sua autonomia política, administrativa e financeira, desfazendo-se, no entanto, de algumas prerrogativas em prol da nova figura política emergente, sendo a soberania a mais notável dessas prerrogativas.

\footnotetext{
${ }^{6}$ Conforme estatuído nos termos do artigo 60, §40, inciso I, da CF: "Não será objeto de deliberação a proposta de emenda tendente a abolir: I - a forma federativa de Estado;".
} 
A divisão de competências trazida pela constituição de 1988, contudo, se baseia em um sistema complexo, onde se intercalam competências privativas e competências concorrentes, cumulativas e não cumulativas. Distribuem-se competências, relegando à União e aos municípios competências expressas e, aos estados, a competência residual. Daí vislumbra-se parte da importância conferida ao ente municipal, pois "aos municípios, cabe essencialmente administrar os assuntos de interesse local, bem como legislar sobre eles. Claro está que nos limites e segundo diretrizes traçadas pelo Poder Federal e, mais raramente, pelo Poder Estadual" (FILHO, 2008, p. 49).

A Constituição Federal de 1988 é o primeiro instrumento jurídico passível de realizar o rompimento com o paradigma da centralização, tendo arquitetado um Estado de caráter mais centrífugo, conferido ao ente municipal significativa autonomia, tendo outorgado-lhes competência para legislar sobre assuntos de interesse local, estabelecer sua própria Lei Orgânica e assumir diversas tarefas constitucionais através dos processos de municipalização.

O município, a partir desse acréscimo de competências, torna-se elemento preponderante na criação de uma nova lógica político-administrativa que enseja uma descentralização dos assuntos de interesse local, especialmente no que tange à criação de políticas públicas próprias, e, substancialmente, tendo o condão de facultar ao poder local, sob a forma de democracia deliberativa, de decidir sobre as matérias afeitas ao seu contexto. Só é possível democratizar e compartilhar poder, quando, de fato, há poder a ser repartido. Daí a importância de se falar em repartição dupla de competências: uma vertical, interinstitucional e outra horizontal, inserida no espaço local próprio, compartilhando o poder entre governo e sociedade.

Há de se ressalvar que a descentralização que se busca efetivar, enquanto estratégia de democratização das ações estatais, não deve implicar a abdicação dos recursos e do poder do governo central, sob risco de aprofundamento das desigualdades regionais, tendo em vista a capacidade heterogênea das diferentes regiões brasileiras tanto de investimento de recursos, quanto de formulação de políticas públicas. Há um discrepância, entre as regiões, quanto ao ritmo e aos resultados da implementação de políticas públicas; quanto à qualidade dos serviços prestados; e, essencialmente, quanto a sua capacidade arrecadatória. A tarefa de superação desse quadro de desigualdades, consubstanciada em objetivo constitucional ${ }^{7}$, não deve estar sob encargo exclusivo dos governos locais (ARRETCHE, 1996).

\footnotetext{
${ }^{7}$ Constituição Federal, Art. 3o: Constituem objetivos fundamentais da República Federativa do Brasil: [...] III - erradicar a pobreza e a marginalização e reduzir as desigualdades sociais e regionais;
} 
Portanto, se constata que a tarefa da Descentralização não impõe o enfraquecimento do Estado central, entretanto, propõe um redimensionamento de suas funções, tanto na regulação das políticas nacionais, quanto na mitigação das desigualdades nacionais, objetivando a compensação das insuficiências locais. Tem-se nisto um novo papel a ser exercido pelo Estado central, no sentido de que o governo federal venha a executar novas funções, relacionadas à coordenação, regulamentação e fiscalização das funções descentralizadas.

Nesse novo contexto de obrigações constitucionais que o município assume, uma das mais importantes é a gestão e o planejamento urbanístico da cidade, devendo observar uma série de princípios constitucionais, como a função socioambiental da propriedade, o direito ao meio ambiente ecologicamente equilibrado e o princípio do não retrocesso ambiental. Também é o município corresponsável pela concretização dos objetivos constitucionais, tais como: construir uma sociedade livre, justa e solidária; e, erradicar a pobreza e a marginalização e reduzir as desigualdades sociais e regionais (CF, Art. $3^{\circ}$ ).

A problemática da urbanização, tema prioritário dentre as administrações locais, perpassa quatro pontos fundamentais a ser gestionados: aceleração do ritmo de urbanização; concentração deste crescimento urbano, especialmente nos países capitalistas periféricos como o Brasil, sem correspondência com o crescimento econômico que se desenvolveu na primeira fase de urbanização dos países de capitalismo central; crescimento desordenado de metrópoles; e, as relações do fenômeno urbano com novas formas de articulação social advindos do modo de produção capitalista. (CASTELLS, 2000, p. 46). Convém determinar o conceito de urbanização aqui adotado:

[...] a noção ideológica de urbanização refere-se ao processo pelo qual uma proporção significativamente importante da população de uma sociedade concentra-se sobre um certo espaço, onde se constituem aglomerados funcional e socialmente interdependentes do ponto de vista interno, e numa relação de articulação hierarquizada (rede urbana). (CASTELLS, 2000, p. 46)

Tal é o desafio dos governos locais. Entretanto, as forças hegemônicas que impedem de concretizar políticas públicas mais justas, bem como o estabelecimento de uma matriz tributária voltada ao equilíbrio das distorções econômicas, manifestam-se igualmente nas esferas nacional e global. A influência e os grupos de pressão que dominam a agenda política também prevalecem no âmbito local, o que implica mais do que boa vontade e possibilidades jurídicas de se estabelecer um novo contexto no planejamento urbano, alinhado aos objetivos constitucionais. Conhecer alguns desses possíveis entraves na correlação de forças entre atores 
hegemônicos e aqueles moradores da cidade ilegal, com desenvolvimento incompleto de sua cidadania, pode indicar caminhos para sua superação.

O próximo ponto abordará o contexto dessa tarefa para os municípios, demonstrando alguns aspectos da crise urbana, da formação das "cidades ilegais" e da dificuldade de garantia do direito à cidade frente aos interesses financeiros globais, à especulação imobiliária e à falta de execução de um adequado planejamento urbano democrático e inclusivo.

\section{A CRISE URBANA E O DIREITO À CIDADE NO CAPITALISMO PERIFÉRICO}

Nos países capitalistas periféricos, boa parte da população urbana é excluída do direito à cidade e do mercado formal, buscando o acesso à moradia por meio do emprego de seus próprios e precários recursos. Além disso, a maior parte da população edifica suas casas sem o conhecimento técnico adequado, sem recurso de financiamento formal e sem observância da legislação fundiária, urbanística e edilícia, cuja prática, comum na realidade latino-americana, é denominada de autoconstrução.

Tal situação se desenrola principalmente pelo fato da força de trabalho nacional não ter incorporado ao salário, especialmente no período desenvolvimentista, o custo da moradia. No Brasil, estima-se que apenas $30 \%$ da população tenha acesso à moradia no mercado privado. Nem mesmo o ganho real do poder de compra do salário e os programas de habitação popular na última década são suficientes para transformar esse quadro, pois o custo da cidade acaba por absorver esse acréscimo com o aumento do custo do transporte coletivo e da especulação imobiliária (MARICATO, 2015).

O planejamento urbano modernista funcionalista, importante instrumento de dominação ideológica, contribui para a consolidação de sociedades desiguais ao ocultar a cidade real e preservar condições para a formação de um mercado imobiliário especulativo e restrito a uma minoria. Abundante aparato regulatório (leis de zoneamento, código de obras, código visual, leis de parcelamento de solo inspirado em modelos estrangeiros) convive coma radical flexibilidade da cidade ilegal, fornecendo o caráter da institucionalização fraturada, mas dissimulada. (MARICATO, 2015, p.85)

O Estado tem papel essencial na produção do espaço urbano, pois controla o fundo público para investimentos, cabendo a ele, sob a forma de poder local, regulamentar e controlar seu uso e a ocupação do solo, seguindo os planos diretores e demais regulamentos aprovados nas esferas legislativas. O Estado consubstancia-se então como o "principal intermediador na distribuição de lucros, juros, rendas e salários (direto e indireto), entre outros papéis" (MARICATO, 2015, p.25). 
No Brasil, o poder social, econômico e político sempre estiveram associados à detenção de patrimônio, seja sob a forma de posse de escravos (até 1850), ou sob a forma de terras e propriedades. O patrimonialismo, ou, a privatização do aparelho estatal encarado como coisa pessoal, está diretamente ligado à desigualdade social histórica, persistente e constante na história do Brasil. A desigualdade ${ }^{8}$ brasileira permanece entre as mais altas da América Latina, o capital financeiro e especulativo, ao disputar e apropriar-se do fundo público, ocasiona uma piora das condições de vida urbana, pois este, em vez de voltar-se à reprodução da força de trabalho, dirige-se à reprodução do capital. Além disso, se aprofunda o quadro de crise com o esquecimento da Reforma Urbana, cujo ponto central é a função social da propriedade, princípio explicitamente constitucionalizado e reforçado no Estatuto da Cidade e na totalidade dos planos diretores municipais e negligenciado nos planos de ação estatal. (MARICATO, 2015)

O peso e a influência das organizações supranacionais, especialmente de caráter financeiro, no âmbito dos Estados, potencializa a exclusão de "áreas físicas, políticas e econômicas frágeis do processo de deliberação do político" e cria novos canais para a colocação de recursos de modo a retirar, paulatinamente, a capacidade de autonomia das comunidades e suas instituições. (LEAL, 2003, p. 50/51)

Os impactos negativos da globalização econômica em países da periferia são muito amplos e manifestam-se de forma muito visível. Agravados, muitas vezes, pelas políticas de ajustamento estrutural, eles manifestamse, quase sempre, na desestruturação de sistemas pobres mas fiáveis de segurança básica, na alteração radical das oportunidades conhecidas de investimento e de emprego e na demissão da função regulatória do Estado na vida econômica, daquilo que ela tinha (quando tinha) de positivo, ou seja, a proteção contra os desmandos do capitalismo selvagem. (HESPANHA, 2002, p. 181)

Pode-se afirmar que o estágio de desenvolvimento de uma determinada sociedade pode ser medido pelo grau de urbanização e as soluções dadas para as questões de ocupação e planejamento urbano, voltadas para a maximização da economia, constituindo os marcos do desenvolvimento contínuo em um determinado modelo de sociedade e de organização capitalista (LEAL, 2003, p. 77). Nesse quesito, o Brasil pode ser descrito como um país capitalista periférico de desenvolvimento incompleto e carente de reformas estruturais de caráter local, público e voltadas à parcela da população historicamente relegada e alijada do direito à cidade.

\footnotetext{
8 "En la región, los países más desiguales por la distribución de la renta son (ordenados de mayor a menor coeficiente) Guatemala, Honduras, Colombia, Brasil, República Dominicana y Bolivia, todos ellos con un coeficiente por encima de 0,56. Por debajo de 0,50 se encuentran Costa Rica, Ecuador, El Salvador, Perú y Uruguay. Venezuela, el país con menos inequidad de ingreso (0,41 de Gini), era, según cálculos para 2009, más desigual que Estados Unidos o el país más inequitativo de la zona euro (Portugal), ambos con un valor de 0,3822." (ONU HABITAT, 2012, p. 45)
} 
A insegurança e os conflitos ambientais urbanos dos últimos anos mobilizaram um consenso pela restauração - ou instauração - da qualidade de vida nas cidades por meio da adoção de políticas públicas que alterem substancialmente a realidade social, especialmente nas áreas periféricas. Some-se a isto o fato de que grande parte dos municípios brasileiros possuem seus territórios ocupados em desacordo com a legislação urbanística, tal qual se deu com a formação do território nacional. Não há uma consciência coletiva urbana ou ambiental engajada da solução das ocupações desordenadas que acabam por degradar o meio ambiente e gerar o caos social (LEAL, 2003, p. 79)

O processo de transnacionalização de capitais e de enfraquecimento dos Estados nacionais, bem como a cooptação dos cofres públicos pelos agentes privados, tendem, invariavelmente, ao processo de gentrificação dos grandes centros urbanos e ao alto custo habitacional, resultantes da especulação imobiliária e da falta de políticas públicas urbanísticas que regulamentem e façam cumprir o instituto da função social da propriedade e do direito à cidade. A três políticas urbanas estruturais, relacionadas à produção do ambiente construído, a saber: transporte, habitação e saneamento, têm sido negligenciadas e dotadas de pouco investimento (MARICATO, 2015, p. 29).

Há uma necessidade de expansão dos princípios político-jurídico democráticos que foram consagrados na modernidade, restritos ao espaço de cidadania formal, para os demais espaços estruturais. A pós-modernidade exige então uma repolitização da vida social, onde a cidadania se articule com a democratização dos demais espaços estruturais. Para tanto, tornase indissociável a vinculação da participação social no processo de planejamento e gestão urbanística das cidades.

Nesse contexto, a edição do Estatuto da Cidade (Lei 10.527/2001) consubstancia-se como um marco na questão urbana nacional, instituindo a gestão pública participativa e que prevê a "gestão democrática por meio da participação da população e de associações representativas dos vários segmentos da comunidade na formulação, execução e acompanhamento de planos, programas e projetos de desenvolvimento urbano", ressalvando ainda que, no âmbito municipal, a gestão orçamentária participativa incluirá a realização de debates, audiências e consultas públicas sobre as propostas do plano plurianual, lei de diretrizes orçamentárias e do orçamento anual como "condição obrigatória para sua aprovação".

A Constituição Federal trouxe a positivação definitiva do direito urbanístico no ordenamento brasileiro, tornando explícito seu campo temático: a política espacial das cidades e instrumentos de implementação; a materialização de conceitos, tais quais: a função social da 
propriedade urbana e o planejamento urbano; seus objetivos maiores, como a regularização fundiária, a preservação ambiental e a sustentabilidade; o desenvolvimento urbano e participação democrática no planejamento urbano; e, finalmente, os instrumentos hábeis ao cumprimento da política urbana, podendo-se destacar as licenças urbanísticas, a desapropriação urbana, a obrigatoriedade do plano diretor ${ }^{9}$ e a edificação compulsória.

O mais importante desses princípios é certamente o da função socioambiental da propriedade e cidade, que, por sua vez, é uma expressão do princípio de que o urbanismo é uma função pública no sentido mais amplo, isto é, a ordem urbanística não é determinada tãosomente pela ordem dos direitos individuais, não sendo reduzível tãosomente à ordem dos direitos estatais. (FERNANDES, 2006, p.11)

No entanto, permanecia a imprescindibilidade de normas que efetivassem os instrumentos previstos constitucionalmente, no intuito de conferir operatividade ao direito urbanístico, bem como, rechaçar alguns dogmas da legislação tradicional, precisamente, a civilista e a administrativa. É nesse contexto que advém o Estatuto da Cidade, objetivando a concretização do direito urbanístico brasileiro e, especialmente, buscando consolidá-lo por meio de conceitos determinados e da regulamentação de instrumentos urbanísticos.

Assim, conferiu-se unidade à política urbana, consagrando expressamente os princípios basilares do Direito à Cidade, conforme prevê o artigo $2^{\circ}$, caput: "A política urbana tem por objetivo ordenar o pleno desenvolvimento das funções sociais da cidade e da propriedade urbana". Desse modo, o direito urbanístico fica:

[...] claramente vinculado a uma visão totalizante de mundo, oposta ao individualismo que, ainda hoje, inspira o direito civil. Ordem urbanística é um conceito caro ao Estatuto da Cidade. Seu primeiro sentido é o de ordenamento: a ordem urbanística é o conjunto orgânico de imposições vinculantes (são as "normas de ordem pública" a que alude o art. 1ํ, parágrafo único) que condicionam positiva e negativamente a ação individual na cidade. O segundo sentido é o de estado: a ordem urbanística é um estado de equilíbrio, que o conjunto dos agentes envolvidos é obrigado a buscar e preservar. (SUNFELD, 2010, p. 54)

Possivelmente o grande diferencial do Estatuto da Cidade seja a abertura democrática do planejamento urbano, compartilhado com a sociedade e ensejando a atuação do espaço local, no âmbito municipal. No entanto, passada mais de uma década da edição do ordenamento, verificam-se inúmeros problemas na efetivação dos princípios democráticos trazidos pelo diploma. Grandes quantidades de municípios, ao editarem seus planos diretores,

\footnotetext{
9 Nas palavras de Mukai (2008, p. 37) o plano diretor é um "instrumento legal que propicia o desenvolvimento urbano (portanto, da cidade) do Município, fixando diretrizes objetivas (metas), programas e projetos para tanto, em um horizonte de tempo determinado.
} 
fizeram-nos com maior ou menor fidelidade aos princípios e diretrizes do Estatuto, gerando resultados diversos, no que se refere ao envolvimento popular nas questões urbanísticas.

Portanto, a democratização da gestão da cidade implica no envolvimento e no fomento da participação dos diferentes setores da sociedade para que estes se apropriem dos instrumentos participativos da gestão urbana, em especial, da composição do plano diretor. Para o atendimento do interesse público e do bem comum, como deve ficar claro, em alguns casos, é preciso que uma minoria abra mão dos seus privilégios para que sejam garantidos os recursos territoriais e materiais que permitirão um crescimento equilibrado e sustentável da cidade (BUCCI, 2010).

Para tanto, uma das questões fundamentais a serem enfrentadas pela gestão democrática do planejamento urbano, face ao déficit habitacional, ao processo de gentrificação e à exclusão de parte da população, cujos salários não contemplam a possibilidade de residir na "cidade legal" e cuja alternativa é procurar áreas degradadas e com risco ambiental, reside na definição de uma política tributária, ainda que de âmbito local, capaz de desincentivar práticas como a especulação imobiliária, aliado a institutos ainda pouco utilizados como a expropriação com pagamento em títulos como sanção à obrigação de parcelamento de solo ou edificação.

Em nível global, uma das alternativas viáveis para a mitigação da crescente desigualdade, segundo Pikkety (2015), é a instituição de tributos sobre o capital e patrimônio, como se verá brevemente no próximo ponto. Ainda que no nível local a previsão de tributos esteja restrita a quatro impostos constitucionalmente estabelecidos, entende-se que é possível utilizá-los estrategicamente - especialmente os de caráter territorial - de modo mais qualificado, inclusive de modo extrafiscal - utilizando a possibilidade de sua progressividade de modo a regular o planejamento e a ocupação na cidade, concomitante a uma gestão democrática do espaço urbano, priorizando o cidadão face aos interesses do mercado imobiliário e de construção.

Não basta, no entanto, ter a ciência do papel da tributação progressiva enquanto mecanismo de mitigação de desigualdades sociais históricas e correção de desequilíbrio de forças entre os atores hegemônicos privados e a construção de uma cidade socialmente equilibrada. Há uma gama de ideias e concepções que podem transformar-se ou não em políticas públicas. Especialmente no que tange a tributação progressiva, há forças políticas ocultas que mantém esse debate quase intocado no Brasil, ao passo que outras políticas públicas redistributivas, implementadas nas últimas duas décadas, têm sido alvo de debates intensos, com boa parte das críticas vindas de setores conservadores da sociedade. Trazer esse 
tópico ao conhecimento público e inseri-lo na agenda pública está entre os desafios dos setores mais progressistas da sociedade, de modo a agregar engajar parte dos excluídos da cidade legal e dos serviços públicos nesse debate público.

\section{POLÍTICAS PÚBLICAS TRIBUTÁRIAS LOCAIS: ELEMENTOS PARA UMA (RE)CONSTRUÇÃO DEMOCRÁTICA DA CIDADE}

Em 2015, os países reunidos na 70a Assembleia Geral da Organização das Nações Unidas (ONU) fixaram uma nova agenda de desenvolvimento até o ano de 2030 - os Objetivos de Desenvolvimento Sustentável (ODS) - que reforça o compromisso de erradicação da pobreza no mundo. A partir disso, um dos grandes avanços nessa agenda em relação aos Objetivos de Desenvolvimento do Milênio (ODM) é o estabelecimento de um objetivo para redução de desigualdades econômicas (OXFAM, 2017). Assim, entende-se que para reduzir a desigualdade é necessário que se abordem as normas culturais que reproduzem a desigualdade e que se refere a liberdade de ação política dos grupos excluídos socialmente.

Si se quiere abordar la desigualdad, se debe hacer frente a los prejuicios, los estereotipos y otras normas culturales que fomentan la discriminación. Esto es especialmente importante en el contexto de las desigualdades horizontales. Combatir la exclusión social y garantizar la igualdad en el acceso a las oportunidades exigirá un mayor fortalecimiento de la libertad de acción y la voz y la participación política de los grupos que sufren desventajas a causa de sus ingresos o de su identidad. Esto les permitirá dar forma a su entorno y a los procesos de adopción de decisiones que afectan a su bienestar. (PNUD,2013)

A Constituição de 1988 inaugurou um projeto de mudança multidimensional no reconhecimento do problema e da necessidade de superação das desigualdades no Brasil, incluindo sua redução e a erradicação da pobreza como objetivos fundamentais da República. Alguns anos após seu advento verificou-se uma redução geral da desigualdade de renda e da pobreza, no entanto, ainda de forma insuficiente. $\mathrm{O}$ incremento de renda da parcela mais pobre não atuou de maneira significativa nas desigualdades brasileiras, pois, ainda existe ainda uma grande assimetria na apropriação do crescimento econômico total (OXFAM, 2017).

Em levantamento recente, verificou-se que, entre 2001 e 2015, os 10\% mais ricos se apropriaram de $61 \%$ do crescimento econômico, enquanto a parte referente aos 50\% mais pobres foi de apenas 18\%. Em relação à renda, o 1\% mais abastado da população recebe, em média, mais de $25 \%$ de toda a renda nacional, ao passo que e os $5 \%$ mais ricos detém o mesmo que os demais 95\% (MORGAN, 2017). Há que se ressaltar que o Brasil é o que mais concentra 
renda no $1 \%$ mais rico, figurando na 30 pior colocação no índice de Gini - índice que mede o grau de concentração de renda de grupos - na América Latina e Caribe ${ }^{10}$ (OXFAM, 2017).

Há um consenso de que o poder público nacional, diante dos objetivos constitucionais fundamentais da república deve, então, desenvolver políticas públicas para enfrentar o problema da crise urbana, da ocupação do solo, e da falta de planejamento urbanístico. Isto porque toda política pública aponta para a resolução de um problema público, reconhecido como tal na agenda governamental. Assim, ela representa a resposta do sistema políticoadministrativo a uma situação da realidade social compreendida politicamente como inaceitável. (SUBIRATS; ET al., 2008, p. 35)

Diante disso, há uma necessidade premente de superação de uma lógica do direito privado, especialmente civilista, diante do caráter público do direito à cidade. Há uma ordem de direito coletivo, permeada por princípios constitucionais, que devem ser priorizados face aos direitos individuais. Essa superação implica esforços também coletivos, pois "esse protagonismo institucional tem como tarefa mais difícil a implementação de suas políticas no multifacetado terreno da sociedade civil, onde a matriz civilista e as filiações à dinâmica econômica estão sedimentadas" (BALDO, 2012, p.134).

No entanto, há de se superar a crença no imaginário do Estado como um Estadoprovidência, que responde de maneira igualitária e automática a todos as demandas sociais, como sugere a visão pluralista da teoria das políticas públicas, em alguns momentos. Certas políticas públicas podem interpretar-se não como uma ação coletiva para tratar de resolver ou aliviar um problema social, mas como simples instrumento para o exercício de poder e a dominação de um grupo social sobre outro. Especialmente no contexto do planejamento urbano, com múltiplos interesses em disputa, essa realidade é mais evidente. Assim, uma política pública pode ser definida como:

una serie de decisiones o de acciones, intencionalmente coherentes, tomadas por diferentes actores, públicos y a veces no públicos - cuyos recursos, nexos institucionales e intereses varían- a fin de resolver de manera puntual un problema políticamente definido como colectivo. Este conjunto de decisiones y acciones da lugar a actos formales, con um grado de obligatoriedad variable, tendentes a modificar la conducta de grupos sociales que, se supone, originaron el problema colectivo a resolver (grupos-objetivo), en el interés de grupos sociales que padecen los efectos negativos del problema en cuestión (beneficiarios finales). (SUBIRATS, 2008, p. 38)

\footnotetext{
10 Segundo o último Relatório de Desenvolvimento Humano do Programa das Nações Unidas para o Desenvolvimento (PNUD) o Brasil é o 10 país mais desigual do mundo, num ranking de mais de 140 países.
} 
Essa definição serve para as políticas denominadas "substantivas", que se distinguem das políticas denominadas "institucionais" ou "constitucionais", que têm como objetivo a reforma ou a descentralização de instituições estatais e não diretamente a solução de um problema social (SUBIRATS, 2008, p. 40).

Como conceber então uma política pública cujo conteúdo possa mitigar o quadro da desigualdade e exclusão urbana, de modo a atender os princípios constitucionais referentes ao espaço urbano, o direito à cidade e, ao mesmo tempo, regular os interesses antagônicos de grupos financeiros e atores globais responsáveis por empreendimentos imobiliários e especulativos em determinadas áreas das cidades?

É evidente que diante da complexidade, da multiplicidade de atores envolvidos e do viés político de uma política pública, não se intenta propor um plano estratégico de ação em forma de política pública, de forma unilateral. Contudo, se busca indicar pontos centrais para um dos possíveis eixos de ação, subsumido aqui no uso da tributação municipal com finalidade extrafiscal e regulatória. A opção pelo viés tributário se justifica, no contexto jurídico e econômico, pelo fato de boa parte dos autores da economia política indicar este caminho, como uma ferramenta eficaz na redução de desigualdades econômicas e sociais, desde que utilizado de forma progressiva e de acordo com a capacidade contributiva.

A injustiça tributária é reforçada pela proporção de impostos diretos - como o Imposto de Renda de Pessoa Física - IRPF e o Imposto Predial e Territorial Urbano - IPTU - e indiretos, que recaem sobre produtos e serviços, geralmente atrelados ao consumo. Pouco mais da metade (53\%) da receita tributária do Brasil é formada por tributação do consumo, que, por ter sua arrecadação diretamente relacionada a itens como alimentação, medicamentos, vestuário, transporte e aluguel, por exemplo, onera de maneira desigual os as pessoas de menor poder aquisitiva, que comprometem a maior parte de sua renda nestes itens. 0 imposto sobre a renda, proporcionalmente mais justo, é responsável por apenas $25 \%$ da arrecadação total. (OXFAM, 2017)

Pikkety afirma que a história da desigualdade é moldada pela forma como os atores políticos, sociais e econômicos entendem pelo que é justo e o que não é, bem como pela influência de cada um desses atores e pelas escolhas coletivas que delas advém, sendo resultado da combinação, do jogo de forças, de todos os atores envolvidos. Assim, o autor entende que a dinâmica da distribuição da riqueza revela um sistema variável que "ora tende para a convergência, ora para a divergência, e não há qualquer processo natural ou espontâneo 
para impedir que prevaleçam as forças desestabilizadoras, aquelas que promovem a desigualdade". (PIKKETY, 2014, p. 29)

As raízes desta situação catastrófica são mais políticas do que econômicas. O mundo produz atualmente perto de 10 mil dólares de bens e serviços por pessoa e por ano, o que significa que, com uma repartição um pouco mais justa, poder-se-ia assegurar uma vida digna e normal para toda a população do planeta, sem miséria, sem fome, e sem as manifestações de violência que resultam da opressão. (DOWBOR, 2016, p.17)

Pikkety (2014, p. 38) afirma que é possível imaginar que instituições e políticas públicas possam contrabalançar os efeitos dessa lógica implacável, adotando, por exemplo, um imposto progressivo sobre o capital, que possa atuar sobre a desigualdade - onde a remuneração do capital represente mais lucro do que o crescimento econômico, representado por ele como "r > g" - alinhando a remuneração do capital e o crescimento econômico, ainda que isso implicasse a adoção um fenomenal esforço de coordenação internacional. Para o autor, o imposto não é nem bom nem ruim em si, mas dependerá da maneira como ele é arrecadado e administrado.

É possível conceber o desenvolvimento de novos modos de organização descentralizados e participativos, bem como formas inovadoras de governança, de modo a permitir e estruturar de maneira eficaz um setor público muito mais amplo do que o atual. Nesse contexto, a adoção de políticas públicas de âmbito local, descentralizadas vertical e horizontalmente, com participação democrática, especialmente dos atores historicamente alijados dos serviços públicos básicos, é uma alternativa primordial na tentativa de romper com a estrutura globalizante dos atores econômicos no planejamento urbano (PIKKETY, 2014, p. 601).

[...] as políticas públicas urbanas estão sendo formatadas para atender às exigências estruturais decorrentes da globalização, o que ocorre em detrimento daquela parcela da cidade que não conta - e jamais contou com políticas públicas provedoras de infraestrutura básica para sua sobrevivência. Nesse contexto é que surge o espaço local como possibilidade de insurreição da cidadania ativa, em que a participação social passa a ser o vetor de uma nova ordem social como contraponto à ordem global que se impõe. (SCHEID, 2008, p. 2)

O imposto não é uma questão apenas técnica, mas eminentemente política e filosófica, e sem dúvida a mais importante de todas. Sem impostos, a sociedade não pode ter um destino comum e a ação coletiva é impossível. Sempre foi assim. No cerne de cada transformação política importante, encontramos uma revolução fiscal. Fazer com que os cidadãos possam escolher soberana e democraticamente os recursos que desejam dedicar aos projetos comuns: 
educação, saúde, aposentadoria, desigualdade, emprego, desenvolvimento sustentável etc. (PIKKETY, 2014, p. 612)

Desse modo, se pode distinguir os impostos em relação a sua proporcionalidade ou progressividade. Um imposto é concebido como proporcional quando sua taxa é a mesma aplicável para todos, sendo uma taxa fixa, ou "flat tax". De outro modo, o imposto é progressivo quando sua taxa é mais alta para os mais ricos, ou seja, para quem possui uma renda, capital ou consumo mais elevado, se aplica um imposto progressivo para a renda, o capital ou o consumo. Esse imposto será menor, por conseguinte, para os mais pobres. Um imposto pode ser regressivo, quando a taxa fica menor, proporcionalmente, para os mais ricos, seja pelo fato de conseguirem meios de elidir, em parte, ao regime normal - legalmente, por meio de otimização fiscal, ou ilegalmente, por evasão - ou porque o regime justamente preceitua sua regressividade (PIKKETY, 2014, p. 614).

Em razão da delimitação temática do trabalho, o objeto de análise serão os tributos de competência municipal, com ênfase para Imposto Predial e Territorial Urbano (IPTU), que adquiriu nova perspectiva após a edição do Estatuto da Cidade, potencializado por "feições de sanções" e sendo vinculado e condicionado aos objetivos do art. 5 do Estatuto ${ }^{11}$.

O IPTU, desde sua instituição em 1946, é de competência municipal originária. Nos termos do artigo 156 da CF, possui função eminentemente fiscal, isto é, a de obter recursos financeiros para a administração pública local, não obstante possa ter função também extrafiscal, como no caso do IPTU progressivo aplicável em terrenos não edificados, como quando utilizado instrumentalmente para desestimular comportamentos em desacordo com a lei e com as diretrizes do plano diretor municipal. O IPTU provém da contribuição de cada pessoa, física ou jurídica, que possua uma propriedade registrada em seu nome, que chega a representar $30 \%$ do total das receitas originárias municipais em boa parte dos municípios brasileiros.

Além da possibilidade de incidência do IPTU progressivo, com aumento de alíquotas conforme os critérios estabelecidos no Estatuto e pela lei municipal, há também a possibilidade

\footnotetext{
${ }^{11}$ Estatuto da Cidade, art. 5을

"Lei municipal específica para área incluída no plano diretor poderá determinar o parcelamento, a edificação ou a utilização compulsórios do solo urbano não edificado, subutilizado ou não utilizado, devendo fixar as condições e os prazos para implementação da referida obrigação.

$\S 1$-Considera-se subutilizado o imóvel:

I - cujo aproveitamento seja inferior ao mínimo definido no plano diretor ou em legislação dele decorrente;" [...]
} 
da expropriação da propriedade ${ }^{12}$ com pagamento em títulos, passados cinco anos da cobrança do IPTU progressivo sem que o proprietário tenha atendido as obrigações inerentes ao parcelamento, edificação ou utilização (LEAL, 2003, p. 113/114). Para esta expropriação, os valores tomados como base serão aqueles indicadores constantes na base de cálculo do próprio IPTU, não guardando relação com os valores praticados no mercado imobiliário, cuja lógica de precificação engloba outros fatores.

Desta forma, entende-se indispensável a adoção de dois pressupostos referentes à tributação territorial urbana, por parte de uma administração municipal que esteja comprometida com o adequado planejamento urbanístico: São eles a atualização constante do valor venal dos imóveis, para fins tributários; e, a aplicação efetiva do IPTU progressivo.

\section{Atualização do valor venal dos imóveis}

O IPTU é um exemplo claro da falta de uniformidade no tratamento tributário nos mais de cinco mil e quinhentos municípios brasileiros. Responsável por quase um terço do total de receitas tributárias próprias em boa parte dos municípios, a tarefa de atualização do valor venal do imóvel é de iniciativa do poder executivo municipal, que o fará diretamente ou mediante comissão de levantamento. Depois de realizado o estudo, o aumento do valor venal - que impacta diretamente na base de cálculo - só pode ser feita por lei. Tal situação leva o administrador municipal a um duplo ônus: enfrentar o descontentamento dos cidadãos contribuintes, face à futura majoração tributária, e a formação de maioria parlamentar para a aprovação da lei.

Desse modo, a realidade brasileira mostra que a atualização do valor venal dos imóveis, na prática, é feita somente mediante o uso de índices de correção monetária e de inflação, o que não reflete, muitas vezes, a realidade do seu valor em virtude da valorização superveniente oriunda de melhorias nos logradouros, ou pela proximidade com grandes empreendimentos,

12 "Art. 8o Decorridos cinco anos de cobrança do IPTU progressivo sem que o proprietário tenha cumprido a obrigação de parcelamento, edificação ou utilização, o Município poderá proceder à desapropriação do imóvel, com pagamento em títulos da dívida pública.

$\S 1$ 으 Os títulos da dívida pública terão prévia aprovação pelo Senado Federal e serão resgatados no prazo de até dez anos, em prestações anuais, iguais e sucessivas, assegurados o valor real da indenização e os juros legais de seis por cento ao ano.

$\S 2$ O O valor real da indenização:

I - refletirá o valor da base de cálculo do IPTU, descontado o montante incorporado em função de obras realizadas pelo Poder Público na área onde o mesmo se localiza após a notificação de que trata o $\S 2$ 으o art. 5o desta Lei;

II - não computará expectativas de ganhos, lucros cessantes e juros compensatórios. [...] 
por exemplo. Uma evidência da discrepância desses valores é que o valor base do imóvel para fins de utilização no imposto cobrado sobre transmissão de bens imóveis (ITBI), geralmente é muito superior ao valor base do imóvel para fins de quantificação do IPTU, ambos de competência municipal.

A falta de regularização fundiária é outra questão que inviabiliza a tributação via IPTU. Alguns condomínios de luxo, por exemplo, edificados sobre lotes clandestinos ou áreas de preservação, por não terem sua matrícula no registro de imóveis, ficam livres da tributação, deixando o município de arrecadar importantes recursos para aplicação em áreas prioritárias. Há uma necessidade premente de os municípios, por meio de sua Lei Orgânica, estipularem uma data limite para realização dos estudos de atualização dos valores venais das propriedades urbanas, seja trienal ou quadrienal, ao passo que a atualização nesse ínterim entre uma avaliação e outra continuasse utilizando os métodos de reajuste por índices inflacionários.

\section{Aplicação do IPTU progressivo contra especulação imobiliária}

A questão da progressividade do IPTU já está prevista constitucionalmente, bem como está inserida de modo específico no Estatuto da Cidade e nos planos diretores municipais. Para a utilização de forma concreta desse instrumento, no entanto, o município tem de contar com a participação ativa da população mais atingida pela exclusão urbana, sendo essa uma "rede temática ${ }^{13 "}$ de atores que devem pressionar sua efetivação. Isto porque os proprietários afetados com a progressividade da tributação, geralmente tem um capital social mais bem estruturado e possuem uma capacidade de articulação e pressão forte frente ao poder público.

Em que pese o imposto ser um tributo não vinculado, ou seja, não tem destinação específica, o governo local tem que empreender esforços para realocar os recursos advindos do acréscimo de receita - tanto da atualização do valor venal dos imóveis quanto da aplicação do instituto da progressividade fiscal - em investimentos nas áreas prioritárias no planejamento urbano, especialmente naquelas onde os serviços públicos sequer chegam e onde os cidadãos se encontram mais alijados da dita "cidade legal". Uma alternativa viável há de ser pensada coletivamente sobre o melhor formato, como aplicar diretamente esses recursos provenientes e as contrapartidas de grandes investimentos imobiliários nas chamadas Zonas Especiais de Interesse Social (ZEIS).

\footnotetext{
${ }^{13} \mathrm{~A}$ rede temática (issue network) reagrupa atores em torno de um problema ou de uma reivindicação, como a defesa de um projeto de lei relativo ao meio ambiente, ao urbanismo, ao transporte coletivo, por exemplo. (MULLER; SUREL; 2002)
} 
As ZEIS são partes do território urbano destinadas, predominantemente, à moradia digna para a população da baixa renda por intermédio de melhorias urbanísticas, recuperação ambiental e regularização fundiária de assentamentos precários e irregulares, bem como à provisão de novas Habitações de Interesse Social. As ZEIS devem estar previstas no Plano Diretor do município e demarcadas na respectiva Lei de Zoneamento, podendo ser tanto referente a áreas já ocupadas por assentamentos precários, como também a áreas a serem demarcadas sobre terrenos vazios. Em caso de existência de assentamentos, procura-se uma flexibilização das normas e padrões urbanísticos, menos elitistas e com viés social, com intuito de regularização desse assentamento por meio de um plano específico de urbanização. Em caso de áreas vazias, a finalidade é o aumento da oferta de terrenos para habitação de interesse social e redução do seu custo.

Apesar do Estatuto da Cidade trazer expressamente uma sessão dedicada à "Gestão Democrática da Cidade", enumerando uma série de instrumentos aptos a oportunizar a participação ativa da sociedade no planejamento urbanístico e na formulação e implementação de políticas públicas urbanas, sua mera positivação não é capaz de transformar o contexto social e engajar politicamente a sociedade civil, especialmente daqueles que historicamente sofreram o déficit de atenção dos poderes públicos. Assim, as administrações locais têm incorporado "mais por exigência legal do que por iniciativa própria, iniciativas que propiciam a participação popular na elaboração dos planos diretores, apenas o fazem formalmente" (FILHO, 2011, p. 292).

[...] disponibilizar espaço de participação é fácil, o difícil é garantir a qualidade desta participação em razão dos interesses envolvidos. Este, talvez seja o maior dilema a ser enfrentado para a efetivação de uma "política urbana" realmente democrática e participativa: a de não transformar a participação em um novo tipo de autoritarismo a serviço de interesses políticos particulares e demandas de grupos mais organizados da sociedade e, ainda pior, legitimado pelo discurso democrático. (FILHO, 2011, p. 295)

Assim, para se levar adiante qualquer estratégia de redução de desigualdade urbana, melhoria das condições de vida das populações marginalizadas, cumprimento da função social da propriedade e regulação do poder econômico imobiliário e especulativo no interior das cidades, torna-se essencial, incentivar e promover a formação de uma cultura democrática de base nas relações de poder, possibilitando que as decisões possam ser articuladas de forma compartilhada no espaço local, ensejando a atuação dos cidadãos enquanto parte ativa do processo de deliberação política. Nesse contexto é essencial o fortalecimento institucional e técnico no âmbito das comunidades locais, de modo a criar as "bases para uma abordagem da 
sustentabilidade empreendida pela comunidade, estabelecendo e fortalecendo mecanismos que permitam a troca de experiência e conhecimentos entre os grupos comunitários em nível local, nacional e internacional" (KUJAWA et al., 2011, p. 248).

É claramente insuficiente atender as formalidades legais de criação de espaços públicos voltados à participação popular, pois, "o grau de envolvimento social e de participação dos indivíduos na definição das políticas públicas depende de motivação, educação conscientização, mecanismos e formas de participação eficiente e que possuam significado para o cidadão (KUJAWA et al., 2011, p. 249)".

Um profundo processo de disseminação e contextualização das propostas aqui tratadas é essencial para a defesa conjunta e a viabilidade de um projeto de democratização urbana. Novas estratégias de envolvimento social, como a realização de audiências públicas e reuniões dos conselhos gestores nos locais onde as populações da "cidade clandestina" residem, podem facultar uma participação de fácil acesso, sem o grau de intimidação e a dificuldade de mobilidade para uma população já carente de recursos. O envolvimento das associações comunitárias e associações de bairros por parte dos gestores locais também são essenciais para a criação de um capital social entre os cidadãos. Isso propicia seu envolvimento e a defesa de seus interesses em num planejamento urbano cidadão e ao desenvolvimento de uma cultura de resistência ao processo de apropriação privada do espaço público, ao processo de gentrificação e a priorização de interesses individuais em detrimento dos interesses coletivos.

Não há como pensar e planejar uma cidade democrática, socialmente justa e coletiva, sem dar voz e propiciar o envolvimento daqueles que fazem parte de uma parte da cidade sem o reconhecimento legal de sua habitação, sem condições ambientais de segurança e alijados da assistência básica de serviços públicos. Como em toda política pública, há grupos de interesse e pressão em jogo para definir o que entra na agenda política. O que se tem verificado nas últimas décadas é um predomínio total dos interesses individuais sobre os coletivos e dos interesses econômicos sobre os sociais. Se é através de regras tributárias progressivas, da maior regulação do poder econômico, do cumprimento dos princípios constitucionais da função socioambiental e do direito à cidade que se conseguirá equilibrar o desenvolvimento urbano e transformar, localmente, o meio ambiente urbano em um espaço mais justo, a concretização desses pressupostos só pode se dar mediante a apropriação coletiva dos instrumentos de participação colocados à disposição, especialmente por parte daqueles que sofrem as consequências da exclusão urbana. 


\section{CONSIDERAÇÕES FINAIS}

Há uma tendência geral, no estado contemporâneo, de descentralização do poder e de valorização da autonomia local, padoxalmente a um momento de intensa transnacionalização de fronteiras e capitais. Nesse contexto, os municípios e as instâncias de menor poder assumem importantes tarefas frente às complexas demandas sociais, tendo papel determinante como esfera contra-hegemônica ao processo de globalização. No Brasil, é partir de 1988, quando se eleva o município a ente federativo dotado de autonomia local e competências próprias, que o espaço local passa a ser um dos protagonistas na concretização dos princípios e objetivos constitucionais.

Portanto, construir uma sociedade livre, justa e solidária, erradicar a pobreza e a marginalização, bem como reduzir as desigualdades sociais são objetivos da República extensíveis aos demais entes federativos. O problema de pesquisa do artigo trata sobre a possibilidade de conceber uma política tributária municipal, calcada na progressividade, apta a desincentivar a especulação imobiliária, a fazer cumprir a função social da propriedade e viabilizar, por conseguinte, uma gestão urbana democrática com inclusão dos atores historicamente excluídos das zonas periféricas urbanas.

Uma das principais tarefas de competência municipal passou a ser o planejamento da ocupação urbana e a ordenação territorial. O grande marco, após a positivação constitucional do princípio da função socioambiental da propriedade, foi a edição do Estatuto da Cidade, em 2001, como normal geral de elaboração dos planos diretores municipais. A tarefa dos municípios, no entanto, é complexa e urgente: a realidade brasileira conta uma grande parte de sua população, especialmente nos grandes centros urbanos, excluída de serviços públicos básicos, ocupando loteamentos irregulares ou clandestinos, com ausência total de planejamento urbano e normas construtivas, em áreas ambientalmente degradadas e com riscos à saúde. A cidade dita "legal" não contempla a possibilidade aquisitiva de parte da classe trabalhadora, cujos salários não cobrem o custo da moradia, fato que foi agravado pela ausência de políticas públicas habitacionais por décadas.

Em que pese essa tarefa ser de ordem global e envolver, em diferentes níveis, os três entes federativos, a questão central do trabalho baseava-se na premissa de que a progressividade aplicada a impostos de competência municipal, especialmente o predial e territorial urbano, poderiam alterar distorções na questão habitacional nas cidades. Para tanto, utilizando-se da teoria de Thomas Pikkety sobre a progressividade dos impostos sobre o capital 
e patrimônio, bem como a análise da teoria de políticas públicas, se entende plenamente cabível a utilização desses instrumentos de tributação progressiva, referente à propriedade territorial urbana, tanto no sentido de cumprimento da função social da propriedade, evitandose a não edificação de loteamentos utilizados para fins de especulação imobiliária, bem como a utilização do acréscimo de receitas - oriundas da atualização regular dos valores venais dos imóveis e da regularização fundiária, por exemplo - no investimento das Zonas Especiais de Interesse Social.

Por fim, para consecução dessas estratégias, é indispensável a atuação do Poder Público local no envolvimento dos atores sociais historicamente excluídos, no processo de deliberação e implementação em uma eventual política pública. Na disputa de antagônicos interesses que circundam o planejamento territorial, cabe aos gestores do campo progressista tentar envolver a sociedade civil, especialmente aqueles que estão à margem da "cidade legal", na tentativa de equilibrar as correlações de forças.

Os municípios estão sob a mesma ideologia e domínio dos atores econômicos hegemônicos, tais quais os Estados nacionais. Não há como superar essa disputa velada sem uma organização social coletiva ampla, a fim de propor e tentar implementar um ordenamento territorial que englobe a dimensão coletiva e o bem-estar social acima dos interesses econômicos. No entanto, não se pode esperar que essa organização surja de forma espontânea, justamente daqueles que sofrem os efeitos de uma organização territorial excludente, que detém um capital social e um poder de pressão reduzido e concentram-se basicamente na sobrevivência diária. Sem o aporte dos governos locais e da sociedade civil organizada, sensíveis às questões sociais e alinhados ao campo progressista, no processo de conscientização e mobilização popular na construção de uma gestão pública compartilhada, os interesses econômicos hegemônicos continuarão a preponderar sobre a utopia de uma gestão democrática da cidade com justiça social.

\section{REFERÊNCIAS BIBLIOGRÁFICAS}

ARRETCHE, Marta T. Mitos da descentralização: mais democracia e eficiência nas políticas públicas? Revista brasileira de ciências sociais, v. 31,1996. Disponível em: <http://www.fflch.usp.br/dcp/assets/docs/Marta/RBCS_96.pdf> Acesso em: 14 Jun. 2017

ALMEIDA, Lindijane de Souza Bento. Gestão Pública e Democracia: Os Conselhos Gestores de Saúde da Região Metropolitana de Natal-RN. In: Revista Democracia e Participação.V.1, n.1. p. 44-72. Brasília: Secretaria Geral da Presidência da República, 2014. 
BALDO, lumar Junior. Direito à cidade: uma possibilidade real a partir do acesso à moradia digna e sua função socioambiental. Curitiba: Multideia, 2012.

BRASIL. Estatuto da Cidade - Lei 10.257/01 de 10 de julho de 2001. Disponível em: <http://www.planalto.gov.br/ccivil_03/leis/LEIS_2001/L10257.htm> Acesso em: 11 jul. 2017

Constituição da República Federativa do Brasil, de 05 de outubro de 1988. Disponível em: <http://www.planalto.gov.br/ccivil_03/constituicao/constituicao.htm> Acesso em: 11 jul. 2017

BREWER-CARÍAS, Allan R. La descentralización del poder en el estado democrático contemporáneo. Córdoba, 2003.2 Disponível em: <http://www.allanbrewercarias.com/Content/449725d9-f1cb-474b-8ab2-

41efb849fea2/Content/l.1.874.pdf> Acesso em 05 jul. 2017.

BRINKERHOFF, D. W.; AZFAR, O. Decentralization and Community Empowerment: Does community empowerment deepen democracy and improve service delivery? 2006. Disponível em: <http://pdf.usaid.gov/pdf_docs/PNADH325.pdf> Acesso em 03 jul. 2017.

BUCCl, Maria Paula Dallari. Fundamentos Para Uma Teoria Jurídica das Políticas Públicas. São Paulo: Saraiva, 2013.

CASTELLS, Manuel. A questão urbana. São Paulo: Paz e terra, 2000.

The new public sphere: Global civil society, communication networks, and global governance. In: The ANNALS of the American Academy of Political and Social Science, v. 616, n. 1, p. 78-93, 2008.

DOWBOR, Ladislau. O que é poder local. Ebook. Imperatriz: Ética, 2016. Disponível em: < http://dowbor.org/blog/wp-content/uploads/2012/06/Dowbor-_Poder-Local-portal.pdf> Acesso em 05 jul. 2017.

FARAH, Marta F. S.Parcerias, novos arranjos institucionais e políticas públicas no nível local de governo. Revista de Administração Pública, V. 35, no 1, 2001, p. 119-145.

FERNANDES, Edésio. A nova ordem jurídico-urbanística no Brasil. Direito urbanístico: estudos brasileiros e internacionais. Belo Horizonte: Del Rey, 2006.

FERNANDEZ, Antoní. Las Políticas Publicas. In: BADIA, Miquel C. (Ed.) Manual de Ciencia política. 3. ed. Madrid: Tecnos, 2006, p. 495-517.

FILHO, João Telmo de Oliveira. 10 Anos do Estatuto da Cidade e a (In)Efetividade dos Instrumentos de Participaçãpo popular. In: MUSSI, Andréa Q; GOMES, Daniela; FARIAS, Vanderlei de O. (Orgs.). Estatuto da cidade: os desafios da cidade justa. v.1 P. 284-298. Passo Fundo: IMED, 2011.

HESPANHA, Pedro. Mal-estar e risco social num mundo globalizado: Novos problemas e novos desafios para a teoria social. In A globalização e as ciências sociais. Boaventura de Sousa Santos (org.) São Paulo: Cortez, 2002. 
KUJAWA, Israel; KUJAWA, Henrique. Estatuto das Cidades Interfaces entre Gestão Democrática e as Políticas Públicas. In: MUSSI, Andréa Q; GOMES, Daniela; FARIAS, Vanderlei de O. (Orgs.). Estatuto da cidade: os desafios da cidade justa. v.1 P. 238-251. Passo Fundo: IMED, 2011.

LEAL, Rogério Gesta. Direito Urbanístico: condições e possibilidades da constituição do espaço urbano. Rio de Janeiro: Renovar, 2003.

MORGAN, Mark. Extreme and persistent inequality: New evidence for Brazil Combining National accounts, surveys and fiscal data, 2001-2015. WID Working Paper Series n. 2017/12. Disponível em: <http://wid.world/wp-content/uploads/2017/09/Morgan2017BrazilDINA-.pdf> Acesso em 01 set. 2017.

MULLER, Pierre; SUREL, Yves. A análise das políticas públicas. Pelotas: Educat, 2002.

ONU-HÁBITAT. Estado de las ciudades de América Latina y El Caribe 2012. Rumbo a una nueva transición urbana. 2012. Disponível em: < http://bit.ly/CidadesALCaribe2012> Acesso em 09 jul. 2017.

OXFAM BRASIL. A Distância que nos une. Um retrato das desigualdades brasileiras. Disponível em:

<https://www.oxfam.org.br/sites/default/files/arquivos/Relatorio_A_distancia_que_nos_une.p df> Acesso em: 28 jul. 2017.

PEREA, Eva Anduiza; BOSCH, Agustí. Comportamiento político y electoral. 2. Barcelona: Ariel, 2004.

PIKETTY, Thomas. O capital no século XXI. Rio de Janeiro: Editora Intrínseca, 2014.

Programa das Nações Unidas para o Desenvolvimento. PNUD. "Humanidad Dividida: cómo hacer frente a la desigualdad en los países em desarrollo." Disponível em: $<$ http://www.redetis.iipe.unesco.org/publicaciones/humanidad-dividida-como-hacer-frente-ala-desigualdad-en-los-paises-en-desarrollo/\#.We9voGcu8ql> Acesso em 28 jul. 2017

SCHEID,Cintia Maria . O impacto da globalização na elaboração de políticas públicas urbanas : uma possibilidade aproximar a cidade a cidadania. Disponivel em: <conpedi.org/manaus/arquivos/anais/bh/cintia_maria_scheid.pdf> Acesso em 09 de jul. 2017.

SCHMIDT, João Pedro. Universidades Comunitárias e Terceiro Setor: Fundamentos comunitaristas da cooperação em políticas públicas. Santa Cruz do Sul: Edunisc, 2017.

SOUZA, Pedro H. "A desigualdade vista do topo: a concentração de renda entre os ricos no Brasil, 1926-2013". Brasília: Universidade de Brasília, Instituto de Ciências Sociais. 2016.

SUBIRATS, Johan; KNOEPFEL, Peter; Et. Al. Análisis y gestión de políticas Públicas. Barcelona: Ariel, 2008.

SUNDFELD, Carlos Ari. O Estatuto da Cidade e suas diretrizes gerais. In: DALLARI, Adilson A; FERRAZ, Sérgio. (Orgs.). Estatuto da cidade: comentários à lei federal 10.257/2001. 3.ed. v. 10, n. 2. São Paulo: Malheiros, 2010. 
Trabalho enviado em 14 de novembro de 2017. Aceito em 23 de fevereiro de 2018. 